\title{
Insight
}

\section{Competing Claims on Natural Resources: What Role for Science?}

\author{
$\underline{\text { Ken E. Giller }}^{1}$, Cees Leeuwis ${ }^{1}$, Jens A. Andersson ${ }^{1,2}$, Wim Andriesse ${ }^{1}$, Arie Brouwer ${ }^{1}$, Peter Frost ${ }^{3}$, \\ Paul Hebinck $^{1}$, Ignas Heitkönig ${ }^{1}$, Martin K. van Ittersum ${ }^{1}$, Niek Koning, Ruerd Ruben, \\ Maja Slingerland ${ }^{1}$, Henk Udo ${ }^{9}$, Tom Veldkamp ${ }^{1}$, Claudius van de Vijver ${ }^{1}$, Mark T. van Wijk ${ }^{1}$, and \\ Pieter Windmeijer ${ }^{1}$
}

\begin{abstract}
Competing claims on natural resources become increasingly acute, with the poor being most vulnerable to adverse outcomes of such competition. A major challenge for science and policy is to progress from facilitating univocal use to guiding stakeholders in dealing with potentially conflicting uses of natural resources. The development of novel, more equitable, management options that reduce rural poverty is key to achieving sustainable use of natural resources and the resolution of conflicts over them. Here, we describe an interdisciplinary and interactive approach for: (i) the understanding of competing claims and stakeholder objectives; (ii) the identification of alternative resource use options, and (iii) the scientific support to negotiation processes between stakeholders. Central to the outlined approach is a shifted perspective on the role of scientific knowledge in society. Understanding scientific knowledge as entering societal arenas and as fundamentally negotiated, the role of the scientist becomes a more modest one, a contributor to ongoing negotiation processes among stakeholders. Scientists can, therefore, not merely describe and explain resource-use dynamics and competing claims, but in doing so, they should actively contribute to negotiation processes between stakeholders operating at different scales (local, national, regional, and global). Together with stakeholders, they explore alternatives that can contribute to more sustainable and equitable use of natural resources and, where possible, design new technical options and institutional arrangements.
\end{abstract}

Key Words: agricultural science; conflict; ecology; level; methodology; natural resource management; scale; social science; sustainable agriculture

\section{INTRODUCTION}

Access to increasingly scarce natural resources lies at the heart of many local and (inter)national conflicts as many resources have multiple use (Hauge and Ellingsen 1998). Land- and waterbound resources not merely constitute differentand often conflicting - productive values, but often also represent distinct sociocultural and political values. For instance, a rural area that has significance as the ancestral home of a community of smallholder farmers may, at another societal level, be claimed as a region of global conservation importance. Major tensions thus exist between global values regarding nature conservation, (sub-) national interests in agricultural production and tourism development, and the sociocultural values and livelihoods of local populations. Although manifesting themselves most concretely at the local level, such tensions over access and use of natural resources span multiple ecological and socioeconomic scales, and involve societal stakeholders with different worldviews who negotiate these competing claims on natural resources across various levels (see: Gibson et al. 2000).

The acknowledgement of this complexity of competing claims on natural resources has profound consequences for the role of science. At the level of understanding it requires, first, an interdisciplinary approach, integrating social and natural science perspectives (Douthwaite et al. 2001, Sayer and Campbell 2004). This is most conveniently phrased in terms of comprehending socioecological systems, as put forward by the thinking of C. S. Holling and others (Gunderson and Holling 2002). 
Second, to acknowledge that natural resources are claimed by stakeholders with different worldviews - and thus, distinct understandings and valuations of resources-implies a shift in thinking about scientific knowledge and its role in society. Itself a product of a particular worldview, scientific knowledge can no longer be considered as neutral, but must be seen as entering societal arenas - at different societal levels - in which knowledge is contested. Scientific knowledge on natural resources thus becomes understood as fundamentally "negotiated."

As has also been argued by others, this redefined position of scientific knowledge in turn impacts on science's role at the level of sustainable natural resource management or intervention in socioecological systems. First, it implies a shift away from linear intervention models, toward more interactive models (cf. Hagmann et al. 2002, Anderies et al. 2006). Second, collective action-based models, such as resource-based stakeholder platforms and community-based natural resource management, often ignore stakeholders' differing worldviews and capacity to influence policy processes. Consequently, the interests of powerful stakeholders tend to dominate. Marginalization and exclusion are, however, not only a result but also a major source of conflict over access to natural resources and a threat to sustainable use. Scientists thus need to actively and strategically engage with specific stakeholders in order to contribute to more sustainable resource use (Edmunds and Wollenberg 2001:232). Third, acknowledging that scientific knowledge is part of societal negotiations, implies a shift away from recommendations on optimal or most equitable resource use toward explorations of future options or scenarios that can facilitate stakeholder negotiation processes on resource use.

Below, we outline an approach for the understanding of and scientific intervention in this complex arena of competing claims on natural resources. We start by arguing for a multi-scale, interdisciplinary understanding of the drivers of conflict over natural resources. Thereafter, we discuss how science can contribute to policy processes. However, it is first necessary to elaborate on the origins of this approach by situating it vis-àvis existing paradigms on natural resource management.

\section{FROM LINEAR MODELS TO NEGOTIATED KNOWLEDGE FOR OPENING UP SPACE FOR INNOVATION}

Problem solving in the agroecological domain has long been based on linear models of both policy and science application. Until the late 1980s, the dominant idea was that policy could be developed in governmental bureaucracies, and then be implemented in a straightforward manner. The role of science in such endeavors was to provide unequivocal predictive knowledge about the functioning of social and agroecological systems, that would allow for rational planning. Furthermore, science was seen as an important origin for new technical and management innovations, which were to be diffused through intermediaries (such as agricultural extension agents) and then adopted by farmers and other resource users (Rip and Kemp 1998, Geels 2002). Since then, it has increasingly become clear that societal actors should not be seen as passive and obedient adopters of science-based policy solutions. Linear modes of operating lost their appeal as they often do not result in appropriate and widely accepted policies or innovations (Scoones and Thompson 1994, Rip 1995, Aarts and van Woerkum 2002). The idea that one could generate unequivocal and uncontested knowledge and understanding of a situation as a basis for rational planning has eroded rapidly since the 1980s, and has been replaced by the idea that it is essential to deal with multiple realities in societal problemsolving efforts (Long 1990, Leeuwis 2004). As a response, both linear "transfer-of-technology" (ToT) approaches and top-down planning and policy models were replaced (at least at the level of discourse) by more interactive modes of thinking and operating. The dominant idea became that societal problem solving requires active participation by stakeholders in order to ensure that relevant contextual knowledge, values, and perspectives are incorporated in policy and technology designs. A range of methodologies were developed. These include, for example, participatory rural appraisal (PRA, see Chambers 1994a, b), participatory technology development (PTD, see van Veldhuizen et al. 1997), participatory learning and action (PLA, see Pretty et al. 1995), interactive policy development (IPD, van Woerkum 1997), multistakeholder platforms (Röling 1994), communitybased natural resource management (CBNRM, see Sultana and Thompson 2005), and integrated natural resource management (INRM, Hagmann et al. 2002, Sayer and Campbell 2004). An important 
aspect of many such participatory approaches is that they strive to reach consensus among stakeholders about desired policy directions and innovative solutions. Inspired by Habermas's (1981) notion of communicative action, it is often assumed that conflicts of interests among stakeholders can be resolved through the development of shared understandings resulting from joint learning and improved communication (Pretty and Chambers 1994, Röling 1996, Fals Borda 1998).

In the last decade, scholars and practitioners have become increasingly critical of the dynamics and outcomes of participatory processes (Mosse 1995, Wagemans and Boerma 1998, Cooke and Kothari 2001). Although disappointing experiences tended to be attributed first to "bad practice" (Pijnenburg 2004), later reflections emphasize shortcomings in the fundamental assumptions underlying participatory approaches. Such critiques include that participatory approaches: (a) have failed to properly anticipate dynamics of power, conflict, and politics; (b) tend to still assume that "intervention projects" introduced from outside are a main carrier of change, whereas processes of self-organization are underrated; and (c) often addressed only the "local" level, whereas higher-level constraints were not taken into account.

Such critiques directly inform our approach to making science relevant to the issue of competing claims on natural resources. Below, we expand on the conceptual underpinnings of the approach and discuss the role of science in the context of competing interests.

\section{Reconceptualizing Participation as Strategic Negotiations}

History has taught us that efforts to induce change usually tend to go along with tension and conflict. This is not surprising as such changes tend to affect the interests of various stakeholders with potentially diverging perspectives and interests, some of whom - usually those whose interests have dominated until then-have a vested interest in maintaining the status quo or current "regime" (Rip and Kemp 1998, Geels 2002). In this context, many studies have shown that participatory trajectories are affected by dynamics of conflict, power, and political strife, and that outcomes are shaped by unequal capacities and opportunities to take part, mobilize resources, and exert influence (Long and Long 1992, Nelson and
Wright 1995, Leeuwis 2000). In Habermassian terms, it has proved impossible to ban power dynamics and strategic action from participatory processes. In addition, it has been argued that power and politics are not necessarily negative, but also needed to arrive at desirable change. Consequently, it is necessary to develop an approach toward participation that does not negate-conceptually and methodologically - the significance of strategic action and conflicts of interest by attempting to achieve broad agreement (Leeuwis 2000, 2004, Edmunds and Wollenberg 2001). Rather, there is need for an approach that (1) recognizes that actors mobilize power and act strategically in relation to existing and emerging conflicts of interests, and (2) attempts to make this productive for solving societal problems (Leeuwis 2000, 2004) by means of (3) using negotiations strategically "with the explicit goal of increasing decison-making power of disadvantaged groups" (Edmunds and Wollenberg 2001:232). As a solution, we propose that the organization of interactive trajectories should be inspired by theories on negotiation and conflict management, rather than only by models of planning and learning. This has significant implications with regard to the "phasing" of processes and the selection of participants and roles, tasks, and guidelines for outsiders (such as facilitators or mediators; see Leeuwis 2000, 2004).

\section{Toward an Integrative Negotiation Process}

Typically, negotiation processes can be subdivided into two broad categories (Pruitt and Carnevale 1993). Many negotiation processes can be described as being "distributive" in nature. In such cases, the various stakeholders tend to hold on to their own perceptions and positions (i.e., little learning occurs), and basically use negotiations to divide the cake (or the pain). In a struggle over land use, for example, wildlife conservationists and farmers can simply agree to allocate some areas specifically to wildlife and others to farming, whereby the party with the strongest power position gets the largest share. Thus, the gains of one party represent the losses of another. According to Aarts (1998) such compromises tend to be relatively unstable because the "source" of conflict remains intact. Other negotiation processes can be labeled "integrative" (Carnevale 2006:416). In such processes, the stakeholders develop new and at least partially shared problem definitions and cognitions on the basis of a social-learning process, resulting possibly 
in the identification of "win-win" solutions among a subset of actors (which may at the same time still be "win-lose" scenario when looked at from other stakeholder positions). The aforementioned farmers and wildlife conservationists may, for example, rephrase the question "farming or wildlife?" into "how to make farming communities benefit from wildlife conservation?" Thus, they may develop joint tourist facilities or a value-added production chain for "wildlife-friendly food products," from which both wildlife conservationists and (some of the) farmers benefit. It will be clear that the latter type of negotiation is of greater interest in situations where there are competing claims. Thus, the approach aims to enhance the contribution of science to societal negotiation processes, and increase the chances that negotiation becomes integrative.

\section{From Planned "Projects" to Self-Organization in Multiple Networks}

Formal "projects" are still a dominant form through which policy makers, international development donors, and science organizations try to organize change. Making these projects "participatory" was seen as a necessary condition to improve their contribution to society, and hence much participation has actually taken the shape of "participatory project planning." Like convention projects, such participatory projects often still reflect the idea that societal change is somehow amenable to control, prediction, and effective management toward desirable outcomes (Long and van der Ploeg 1989). Matching the rise of non-linear and non-equilibrium-"new ecology" - thinking in ecological sciences (see Scoones 1999), it has been argued that societal change is a much more messy and unpredictable process, in which change emerges eventually as the unintended outcome of numerous intentional actions in different societal networks, which interact with each other in complex ways (Sharpf 1978, Giddens 1984, Sayer and Campbell 2004, Castells 2004). Change, then, is not realized in the arbitrary, isolated, and formalized space of a (participatory or non-participatory) "project," but arises from multiple interactions in and between networks whereby phenomena such as coincidence and self-organization play a major role (Aarts 2007, van Gunsteren 2006). In line with this, our proposed approach is not based on the idea that stakeholders should participate in scientific endeavors, but that scientists need to liaise with established networks and seek opportunities to contribute to them.

\section{The Need for a Multi-Scale and Multi-Level Approach}

As change occurs simultaneously in multiple societal networks, it is clear that deliberate efforts to stimulate change cannot usefully focus on a single network or societal level. In many participatory projects, however, there has been a tendency to focus on the "local" level. The emphasis was on working with groups of land users (farmers), or with "communities." This has tended to ignore that the space for change at such a level tends to be constrained or facilitated by processes occurring in other arenas, or higher societal levels. As is visualized in Fig. 1, responses or innovations of local stakeholders or communities in the face of changing circumstances are constrained by policies and regulations at many different levels. For example, international policies on trade barriers and tariffs have a strong influence on prices a farmer in Africa may obtain for produce, particularly if dealing with a commodity also produced in North America. At regional and national levels, markets and regulations such as the gazetting of prices have further influences on prices for both inputs and produce. Lastly, local infrastructure - such as roads and the existence of agricultural suppliers buying farm produce, selling inputs, or getting produce to the market-structures the possible responses at the local level.

A fundamental premise is, therefore, that existing constraints at different levels need to be addressed simultaneously to increase the "innovation space" for local responses. That is, desirable change may emerge when societal negotiation processes in and between networks lead to a balancing of local entitlements, national developmental interests, and global environmental concerns with sustainable use strategies. In this light, a multi-scale and multi-level analysis is central.

\section{THE ROLE OF THE SCIENTIST IN SOCIETAL NEGOTIATION}

The multi-level and multi-scale nature of conflicts over natural resources as discussed above requires that solutions cannot be limited to the introduction and management of new technologies. They also 
Fig. 1. Global and national policies structure the space within which local responses can be generated. Local "innovations" or responses depend largely on available local resources, but are constrained or enabled by policies and regulations at higher levels. Alleviating constraints at only the national or local level may have no beneficial effect if constraints at the regional or international level are not addressed. The feedback or influence from the local level to higher levels is often very weak, whereas influences from national to regional and global levels are often stronger. A key aim of analysis is to identify enabling policies that can create a greater space for local innovative responses, and strengthen local communities' influence at higher scales.

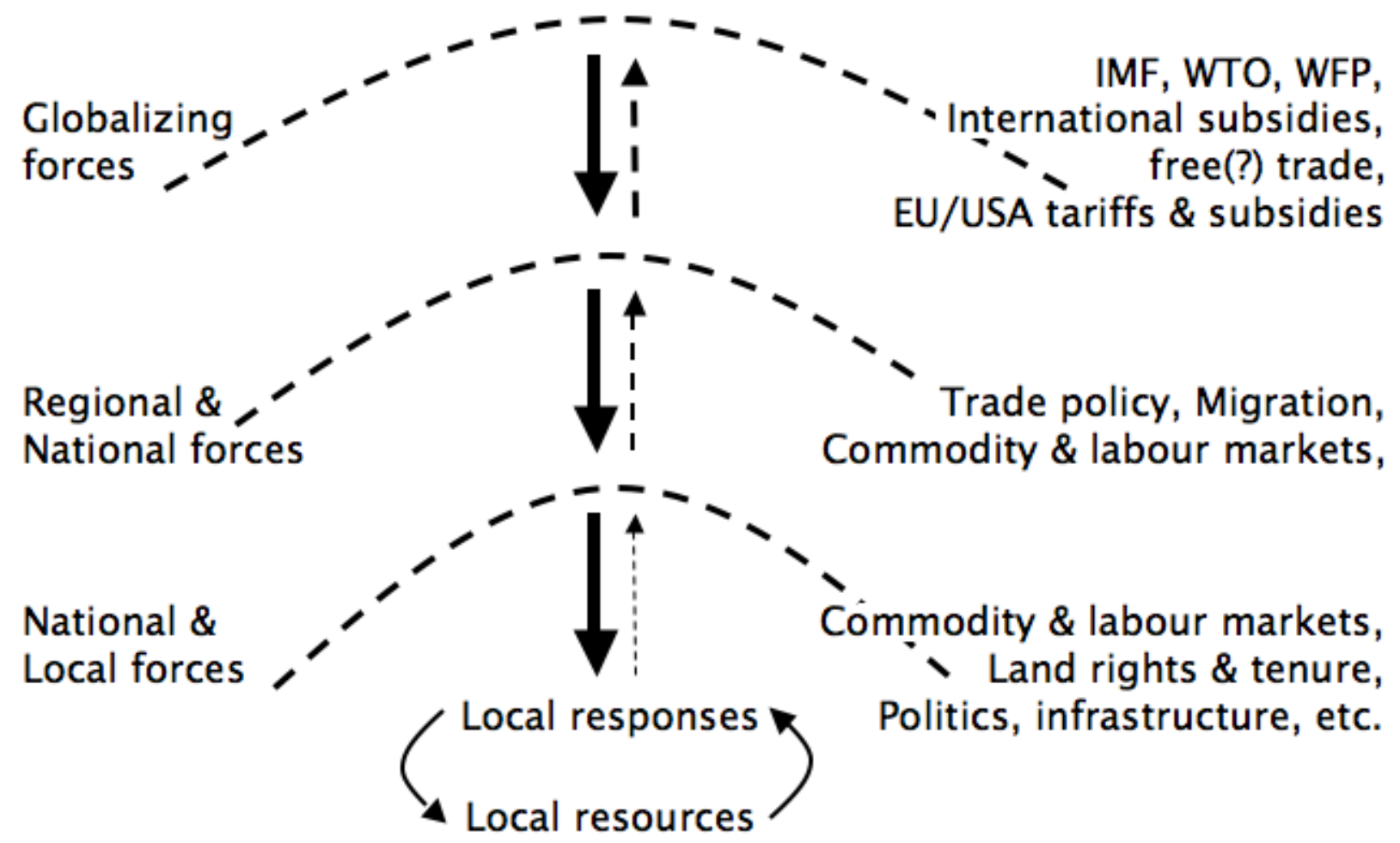

require a focus on new institutional arrangements and alternative modes of thinking among stakeholders operating at different levels of governance. A more encompassing approach such as this reflects current thinking on innovation and transition (Smits 2002 ,Berkhout et al. 2003, Grin et al. 2004). Negotiating change in such a context is seldom a rational and ordered process. More often it is partial and political, and shaped by existing policies and practices, vested interests, and historical precedence. Compliance with agreed policies is arrived at through coercion or compromise, frequently negotiated informally and only later formalized. Moreover, the negotiation process itself is often constrained by asymmetries of knowledge, power, and influence; different attitudes to and perceptions of risk; individual and institutional inertia; and considerable uncertainty about the outcomes of different options. Concerns for equity in the distribution of environmental and other costs, benefits, and risks are often secondary. Below, we discuss some broad implications of operating in such an environment for scientists who want to contribute to societal negotiation processes. 


\section{Engaging with Society}

Competing claims on natural resources involve complex situations where uncertainty is high and where different values and interests are at stake. Typically, policy views are contested in these situations, as are the knowledge claims used by different categories of stakeholders to further their positions. In such situations, scientists can still contribute to the bridging of knowledge gaps and the development of common problem definitions (Hoppe and Huys 2003, Jasanoff 1990). However, it requires scientists to operate in a different mode than is currently dominant. When both uncertainty and decision stakes are high, Funtowicz and Ravetz (1993) argue, scientists need to engage in what they term "post-normal science;" research that is embedded in interaction with relevant societal stakeholders. Transparency is essential when analyzing the claims of competing stakeholders, as is collaboration with them when identifying research problems, exploring suitable options, and, eventually, designing multi-faceted solutions. Societal stakeholders, then, become part of an extended peer community, in that science is answerable to them as well as the more conventional peer review (Funtowicz and Ravetz 1993). This understanding of the role of science resonates strongly with Gibbons et al. (1994) and with the discussion of future-oriented research of van Ittersum et al. (1998), who use causality and uncertainty as separating variables to typify different forms of future-orientated research.

\section{Improving the Quality of Societal Negotiation}

In the context of competing claims on natural resources, the quality of negotiation among stakeholders is often far from optimal in terms of equitability, bargaining power, representation, and compatibility of argumentation skills. Moreover, access to knowledge on interrelations and dynamics in complex systems is often lacking (Cash et al. 2006). Researchers must cooperate with user groups, NGOs and other bodies who are in a position to facilitate negotiations, and can improve the quality of negotiations, by:

- addressing questions and uncertainties experienced by, in particular, weaker parties;

- bringing in perspectives from elsewhere;
- making mental models and assumptions explicit and assessing them. This may sometimes imply that the solution space is smaller-wishful thinking is dismantled;

- $\quad$ widening the space within which solutions are sought, and;

- facilitating the joint creation of objects and experiences that can serve to build bridges between diverging perspectives, and which may become common points of reference (Cash et al. 2006) (i.e., "boundary objects").

On the basis of such inputs, negotiations may shift from being merely distributive, to being integrative as elaborated above. Thus, scientists may contribute toward changing the dynamics in complex adaptive systems by introducing new insights, information flows, and feedbacks into the human component of the system that may eventually change interactions and emergent properties of the system as a whole (see Anderies et al. 2004).

\section{The Value-Driven Nature of Research}

By stimulating (coalitions of) stakeholders to gain access to new insights and perspectives, scientists can enable the development (i.e., construction) of negotiated knowledge by stakeholders, on the basis of which they may engage in complementary courses of action. Clearly, such knowledge and understanding by stakeholders are not neutral or objective, as they tend to be "colored" by cultural understandings, perceived - and partially sharedinterests, and the wish to use it in opposition to the representations of reality put forward by opposing stakeholders. Scientists too, must accept they cannot be neutral. Even if one tries to answer questions as "objectively" as possible, research questions are always value driven (Alre and Kristensen 2002). This becomes most apparent where competing claims arise, as the problem views of, for example, farmers and nature conservationists are inherently different, which leads them to experience different uncertainties, and thus ask different questions. Given the fact that ongoing negotiation processes are not necessarily fair and equal, scientists who wish to improve the quality of societal negotiation may need to decide on whose questions to address. In our case, the conviction that sustainable resource use (critically) depends also on those resource users who are marginalized in stakeholder negotiations 
results in priority being given to questions asked by weaker parties or interests. This requires that scientists are able and willing to carry out stakeholder analysis and oversee the playing field.

\section{Interdisciplinary Cross-Scale Analysis}

As outlined above, we are dealing with negotiations at and between different societal levels and with complex systems that can be approached from different disciplinary and scale perspectives. In order to contribute to societal negotiation, therefore, scientists need to focus on integrating agronomic, ecological, economic, sociological, and spatial dimensions across different hierarchical levels and scales of analysis. In doing so, all relevant levels of policy influence, from international treaties and trade negotiations to local bylaws and customary laws, are addressed. Scenario analysis constitutes a useful tool to make potential effects of potential policy changes at higher levels transparent in terms of their influences at the local level, and to understand how changes in natural resource management at the local level can influence higher levels in ecological or social hierarchies.

Recognition of the need for interdisciplinary approaches to understanding resource use and the problems in achieving synergy are not new insights (di Castri and Hadley 1986, de Wit 1994, Moss 2000, MacMynowski 2007). A myriad of terms has been developed to describe collaborations between scientific disciplines, ranging from multidisciplinary to unidirectional and goal-oriented interdisciplinary research and transdisciplinarity, which includes collaborations with societal stakeholders (policy makers, resource user groups, etc.). In the context of competing claims on natural resources, we consistently refer to (goal-oriented) interdisciplinary and transdisciplinary research for three reasons: (1) the complex social and biophysical problems addressed demand the integration of knowledge from a range of disciplines; (2) new insights are more likely to occur when scientists from different disciplines enter deep interactions with each other; and (3) such collaborations extend beyond the field of science as engagement with societal stakeholders is a prerequisite for the more modest role for scientists we outline here: that of contributors to stakeholder negotiation processes.

\section{Being Modest and Anticipating Societal Response}

Although there are good reasons to assume that science may contribute to enhanced societal negotiation, this is far from easily achieved. In politically laden processes, insights generated through research can easily be ignored, warded off, misinterpreted, or used selectively by stakeholders as weapons in their struggle to define the problem or impose a certain solution. Contrary to many scientists' expectations, few policy makers are waiting for scientific advice. Their perspectives on issues often differ from those of scientists. Consequently, scientific research seldom directly provides the kinds of knowledge and understanding needed for effective public policy. Scientific "recommendations" usually only stand a chance when these are well grounded through consultation with a wide range of stakeholders. Awareness of this reality should not deter scientists wish to use research to help solve complex problems, but must shape the way in which we go about our work. In doing so, we should not have naïve expectations, but should remain modest about our possible contribution and anticipate that our activities and insights will be mobilized opportunistically in political strife in all sorts of unexpected ways. In the next section, where we present the key building blocks of the proposed approach, we also highlight some operational strategies for minimizing problems and creating optimal conditions for the use of the research findings in stakeholder negotiations.

\section{A METHODOLOGY FOR INTERACTIVE SCIENCE: A "NE-DEED" RESEARCH CYCLE}

Acknowledging this renewed role of science vis-àvis stakeholders has important consequences for the organization of the research process. Seeking to feed into negotiations between stakeholders entails an ongoing process of engagement and negotiation with stakeholders right at the start of the initial research phase. Hence, NEgotiation becomes the central feature of research into competing claims on natural resources that can analytically be divided into four interactive phases: Describe, Explain, Explore, and Design (Fig. 2). Below, we describe the four main phases of the research cycle, before focusing on the central role of negotiation. 
Fig. 2. The analysis of competing claims on natural resources: an iterative cycle of stakeholdernegotiated research phases (NE-DEED).

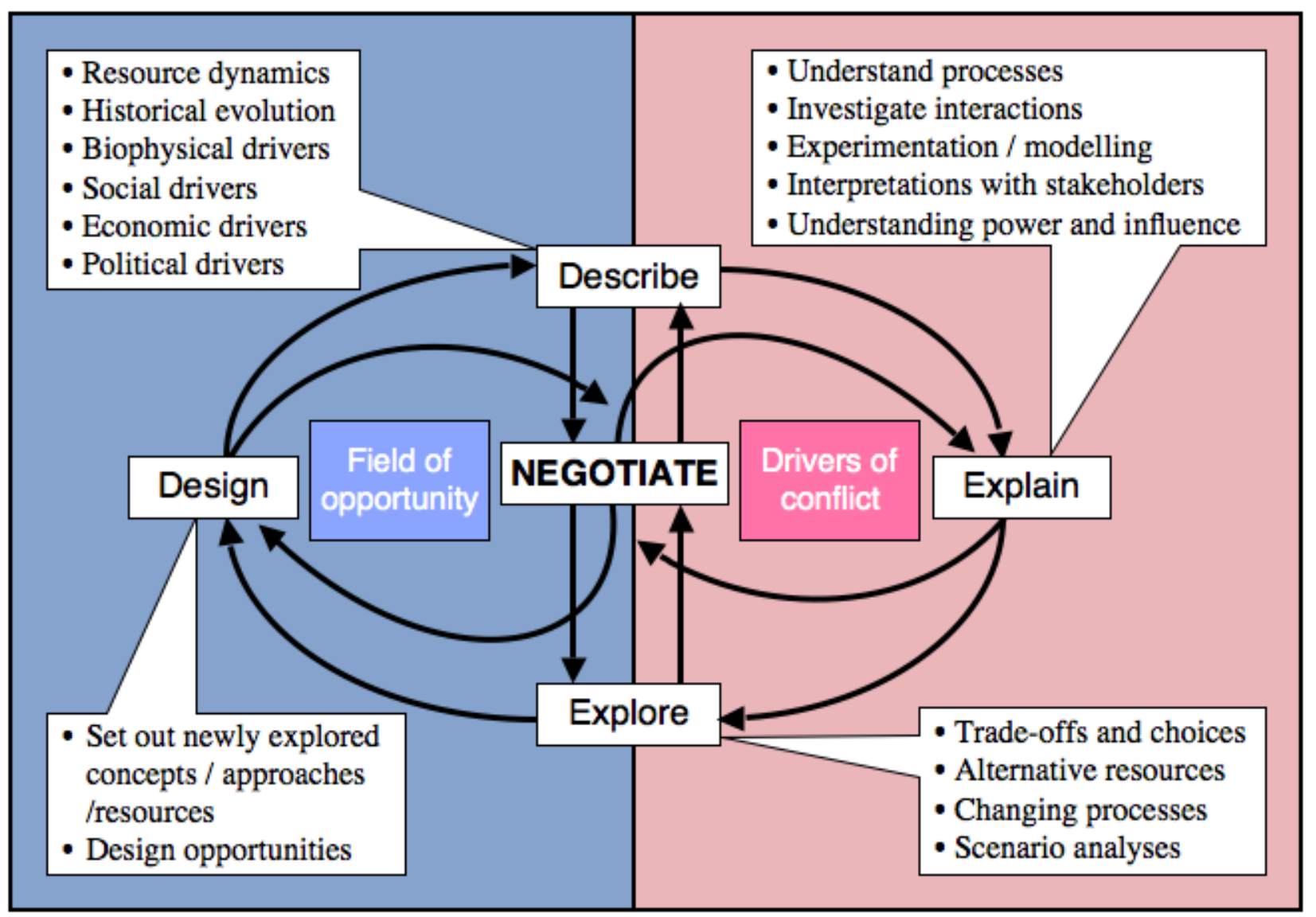

\section{The Research Cycle (1): Describe}

Initially, the focus is on working with stakeholders at different levels, considering their positions (of power) in different networks, worldviews, and understandings of and trends in resource use. The descriptive aspects of the research involve quantifying resources and their dynamics from both current and historical perspectives placed in the agroecological, socioeconomic, and political setting. Furthermore, both agroecological and socioeconomic data are collated. Essential data not available from existing surveys or databases need to be collected. Subsequently, a quantitative description is made about system properties to gain more insight in current and past system functioning. Simultaneously with the quantitative analyses, some system properties are described more qualitatively, aiming to bring out the different socioculturally informed definitions and meanings of resources among stakeholders. Thus, hidden claims on resources-that may not even be informed by productive considerations, but by specific sociocultural orientations (Andersson 1999, Hitchcock 2002)—will be identified, differentiated by socioeconomic status, gender, and the degree by which such claims are articulated in multi-stakeholder platforms. The key focus is on identifying the various drivers of competing claims and specific social and cultural interpretations and constraints that determine the thresholds at which these claims become apparent. Understanding of the historical dynamics of claims may provide clues on how future developments may be shaped. Whereas 
research is focused on specific regions and villages, possible feedbacks and relationships between the different hierarchical levels can be explored through data analysis and literature review, and through discussions with key stakeholders at various levels.

Some initial descriptive questions that guide research are therefore:

- What natural resources are (potentially) available in the research area and what are the competing claims on these resources?

- How are the various socioeconomic and agroecological drivers of competing claims understood, translated, and given meaning in social interaction and policy interventions?

- What institutional arrangements-at different levels - regulate access to and allocation of natural resources, and which stakeholders and claims are included or excluded?

- What are the contested knowledge claims and gaps in understanding that stakeholders experience in resource-use negotiation?

These kinds of questions guide the initial research phase but they are revisited during iterations of the research cycle.

\section{The Research Cycle (2): Explain}

Different disciplinary perspectives and methodologies, ranging from explanatory modeling approaches to narrative analysis, are employed to develop greater understanding of the socioeconomic and agroecological processes that drive and influence competing claims. Understanding resource dynamics and competition by working together with the stakeholders is essential. This requires quantitative analysis using explanatory or statistical methods to test interpretations and relationships suggested by different stakeholders. It is important to have sufficient content (data) to develop a sound understanding of processes, and to triangulate sources of information to reveal the nature of the claims on resources. This will also lead to insights into the validity and potential impact of certain claims. Intense interaction within and between the interdisciplinary researchers and stakeholders is organized to develop an integrated understanding and fusion of theoretical perspectives.
In this phase, research systems analysis is used, in combination with a range of modeling tools to enable exploration of interactions between stakeholders and components of complex systems. We rely on modalities for loose coupling of system approaches, not building large complex models. The most important role for models is to improve conceptual understanding-the first sketch or cartoon of how a system is constructed and functions is often as important as the detailed analysis that follows. Models may be used in two ways. First, simple approaches such as fuzzy cognitive mapping (e.g., Khan and Quaddus 2004) allow complex systems to be analyzed by identifying major driving factors and system variables and their positive or negative influences on each other, and by calculating the outcome of these interactions, including feedbacks. This approach helps in understanding the perspectives of different stakeholders and in explaining the standpoints of others, as well as the potential (unexpected) consequences of their actions. In essence, these simple systems diagrams serve as a means of arriving at a shared (negotiated) understanding of complex management systems. The second way of using models is to adapt approaches from the natural and social sciences to conduct more rigorous quantitative analyses using existing dynamic synthesis models as well as simplified models (Carpenter et al. 1999) to explain processes. Emphasis is on setting up and testing integrated approaches such as the trade-off model (Stoorvogel et al. 2004) and the framework for analysis at farm/ livelihood-scale NUANCES (Giller et al. 2006). These analyses may form the basis for the exploration of alternatives in the next step.

Strong interdisciplinary interaction is foreseen in the analysis of the effects of current and future landuse policies using the different approaches. The outcomes of the detailed process-oriented models will be used in simplified quantitative models or in qualitative reasoning, in which interactions across scales will be represented in more formal ways. Competition concepts developed in ecology may also be useful, as well as quantitative ecological models, which describe competition for limited resources.

The initial explanatory questions include:

- What are the underlying socioeconomic and agroecological processes that drive and shape resource conflicts and resource use? 
- How do agroecological and socioeconomic processes occurring at different scales and levels interact with and influence each other?

- Which levels and processes are most relevant for changing resource dynamics?

- How do stakeholders (including scientists) interpret and explain the dynamics of resource conflicts and why?

\section{The Research Cycle (3): Explore}

The key task of exploration is to develop scenarios with stakeholder groups across hierarchical levels. Particular attention is paid to potential trade-offs and synergies among the strategies for managing competing claims over territories and people. The mental and quantitative models developed earlier can be used to explore choices based on these options and trade-offs. Agent-based models (e.g., Bousquet and Le Page 2004, Bousquet et al. 1999) of the impacts of stakeholder behavior under different circumstances, and their feedbacks, can be helpful in identifying likely scenarios, realistic options, thresholds for sustainable natural resource management and poverty reduction, and constraints on these. The development of sensible scenarios can only be done successfully with participation of all relevant stakeholders (Kok et al. 2006). Qualitative methods, including the analysis of narratives, situations, and networks, can be used to gain further insight into these scenarios and trade-offs.

These exploratory activities can be integrated with and complemented by the use of methodologies such as Future Search (Weisbord and Janoff 1995, see Table 1), Search Conferences (Emery and Purser 1996), and the Sustainable Technology Approach (van Kasteren 2002), which are geared toward developing common visions and identifying actions that may be taken in the short term to achieve these visions.

These approaches encourage stakeholders to set aside current problems, concern, and issues and instead focus on a point in the relatively distant future. Looking at the past helps stakeholders analyze how the present has been shaped, which phenomena are persistent, and which larger trends can be identified. When combined with an assessment of what different stakeholders find positive and negative about the present, examining trends may help them speculate about more and less desirable characteristics of what is likely to happen in the future if no significant changes in action patterns and modes of coordination take place. Often, this helps foster a general sense that "something must be done," even if stakeholders still disagree about what that might entail. From there, the focus shifts toward generating ideas on how the future could look in 5 to 20 years in contrast to the scenario that is deemed likely. Clearly, this is where science can play an important role to avoid future thinking from being purely speculative and to allow explorations of future scenarios. Also crucial at this stage is understanding how new interpretations of possible scenarios or futures are given meaning in interactions within and between stakeholder groups. The difficulties in arriving at a shared vision of complex problems should not be underplayed, and substantial interaction is needed to allow for different viewpoints to be aired. When different stakeholders can identify sufficient commonly attractive elements in specific scenarios, they can start to reason back to the present ("backcasting") by asking: "What can/must we do to improve the chances of arriving at a more desirable future?" This is where issues of (coordinated) action planning and design become significant.

The initial explorative questions that guide the research are:

- What are the likely long-term consequences of current trends and dynamics?

- What possibilities exist at different levels that could enlarge windows of opportunity?

- Which trade-offs between stakeholder objectives are associated with differential scenarios and options from a multi-level perspective?

- How can different stakeholders' interpretations of alternative future scenarios be understood in relation to their interests and value orientations, and as outcome of their mutual interactions?

- What ecological, technical, social, economic, institutional, and political obstacles may be encountered in the process of realizing possible options? 


\section{The Research Cycle (4): Design}

At the end of the exploration phase, a crucial decision has to be taken. Does the exploration suggest that, within the chosen research/ stakeholders configuration, sufficient options space can be created for reconciling competing stakeholder claims and achieving a more equitable distribution of natural resource use? Or is the creation of sufficient options space conditional on policy changes at higher levels that seem unattainable in the existing configuration?

If the answer to the first question is affirmative, a design phase can follow. Insights and results from the explanation and exploration activities can be used in an iterative design process of "prototyping" (cf. Vereijken 1997). Societal stakeholders need to negotiate and agree upon coherent social, institutional, and technical options across different levels. Together these options may form effective sociotechnical innovations that contribute to more equitable and sustainable use of natural resources. The outputs from modeling can be used to give stakeholders feedback about their own behavior and choices. Backcasting is useful for mapping out pathways for transition. This will prevent the process leading only to agreement on an acceptable or Utopian system state without any action being taken. The prime responsibility for making design choices thus lies with societal parties, but scientists can help stakeholders understand the positions of other stakeholders and the likely outcomes of their choices. Visualization and other learning support strategies will be useful for communication with stakeholders.

If sufficient innovation space for reconciling competing claims cannot be created without policy changes at higher levels, which are difficult to achieve, another approach becomes imperative. Stakeholders and scientists should then determine which changes at higher levels would be needed and use scenarios to show how they would influence the innovation space at lower levels. This still involves design, but of regional or global arrangements that cannot be attained in the framework in which the research and negotiations are currently proceeding. Careful reflection is needed on how to cope with this situation. One possibility is to "outsmart" the higher-level constraints by finding a niche that could still be used to widen the innovation space in this case, although there may be little room for repeating the experience in comparable situations in other places. This should then be made explicit, and the exploitation of this niche should be combined with a common appeal by researchers and stakeholders to relevant audiences to change the higher level conditions concerned. For example, stakeholders who increase their options by forming a "sustainable" marketing chain that exploits a limited niche market could combine this activity with advocacy of global arrangements, stimulating the transition to environmentally and socially sustainable production of the commodity concerned. Another possibility is to redefine the research/stakeholders framework to include bridgeheads from where the conditions at higher levels may be influenced. An example is a proposed transition to sustainable cocoa production, where participatory technology development at the local level and institutional development at the national level were combined with the exploration of possibilities for cocoa supply management at the international level (see Koning and Jongeneel 2006). In such cases, it may be necessary to involve other disciplines and stakeholders at higher levels (e.g., regional farmers' unions), and to link to mobilization processes by which less-powerful stakeholders are organizing themselves at supralocal or supra-national levels. When conditions at a higher level are severely constraining, however, continuing to focus solely on local levels may become sterile. For instance, as long as international payments for biodiversity conservation or carbon sequestration remain limited, efforts at a more sustainable reconciliation of interests of environmentalist NGOs and those of local populations may be doomed to fail. There is a considerable risk that activities that focus on local solutions without addressing constraints at a higher level will reproduce or exacerbate existing inequalities and power relations; e.g., without supply management at higher levels, participatory development of better farming practices and marketing chains at the local level repeatedly cause new overproduction and price falls in world markets of crops such as cotton, coffee, or cocoa. In such cases, cooperation and negotiation with stakeholders result in perverse effects, which are what Robbins (2003) termed "fixes that don't work."

The initial questions guiding the interdisciplinary research are:

- What options (technical, social, institutional) do stakeholders at different levels wish to experiment with? 
- What are the criteria that options must meet to be of interest to different stakeholders?

- What gaps in understanding exist in relation to the chosen options and criteria and the (various kinds of) obstacles associated with these?

- What possibilities exist to conduct collaborative experiments with (technical, social, institutional, managerial, etc.) options and solutions?

Iteration within the design stage, as well as feedbacks and feed-forwards to other tasks within the approach are assumed to eventually lead to the development of coherent multi-level innovations. In this respect, the research methodology also operates as a complex adaptive system experiment.

\section{THE CENTER OF THE RESEARCH CYCLE: NEGOTIATE}

As indicated in Fig. 2, all research activities are seen as embedded in societal negotiation processes, which are understood as ongoing in different (including policy) arenas and networks. It is an integral component of complex adaptive systems dynamics, in which different kinds of information and feedbacks are generated and processed. In such arenas, problems, opportunities, options, and tradeoffs are discussed, agreements arrived at, and decisions made. As explained earlier, societal negotiation processes are often of limited quality, and science can assist in making them more equitable, explicit, concrete, creative, and integrative. However, as signaled earlier, there are various pitfalls and risks that scientists must anticipate. In this section, we highlight some operational strategies to create the conditions for the use of the research findings by stakeholders.

\section{Selecting Stakeholders}

A number of important issues arise concerning with whom we work. An important ethical and political principle is that we aim eventually to contribute to the empowerment of vulnerable groups. At the same time, we also recognize the need to work with others, or maintain good relations with others, if the aim is to foster simultaneous change in a multi-level network of actors. Furthermore, a critical condition for integrative negotiation is that negotiating parties (come to) feel interdependent on each other in achieving solutions to their problems (Pruitt and Carnevale 1993).

The stakeholder analysis done during the "Describe" phase is aimed at identifying networks of interdependent stakeholders at multiple nested levels, and also at helping delineate the competing claims. From this, we can define preliminary boundaries in relation to both. A decisive criterion is that levels and actors must be included who (can) have a direct and meaningful influence on the context in which local actors operate, and also who can be effectively involved. It is not likely, for example, that the European consumer would be involved in research on beef production in Botswana. It might be important, however, to involve meat exporters or meat certification bodies who can make a difference in organizing the beef chain. In turn, these institutions could be strongly influenced by the eating preferences of consumers in Europe. Furthermore, the stakeholder analysis will guide us in identifying which actors, networks, or coalitions of actors can be productively worked with to address the objectives of reducing poverty and fostering sustainable and equitable change, and which actors are in a position to leverage or block change, and thus must be liaised with. The identified stakeholders are likely to include: local residents with different livelihood styles; community-based organizations, leaders, and representatives; a variety of sectoral policy makers and administrators at local, regional, and possibly national levels; various parties involved in production chains and processing of products; NGOs; service providers and intermediary organizations; custodians of public goods; and local, extra-local, and national mass media.

It is to be expected that several of these stakeholders will not yet feel interdependent on each other, and moreover, that conflict can be intense at the outset. Bringing together stakeholders who have strongly competing interests too soon is likely to exacerbate conflict rather than assist in resolving claims through developing new options and opportunities (see also Edmunds and Wollenberg 2001). We recognize that scientists' role is to contribute analyses and knowledge, to interact with and learn from the stakeholders, to provide advice, and to question positions. Therefore, we work together with stakeholder groups in developing future 
visions and understanding opposing positions before attempting to assist in bringing groups together for negotiations.

\section{Becoming and Remaining Legitimate}

Scientists are not naturally well placed to work with societal stakeholders on competing claims on natural resources. Even if they succeed initially, they can easily become compromised by, for example, being viewed as partisan, defending specific interests or interest groups. This risk is exacerbated when they choose to work on behalf of weaker parties. Several strategies can be used to remain acceptable to different parties.

First, work primarily with those interests and initiatives identified during the earlier "Describe" and "Explore" phases, offering scientific services to the stakeholders involved. Agree beforehand on the processes, roles, and rules of engagement. Help create interfaces and links among the various parties concerned, remaining committed to working with local leaders, but recognizing that such leaders may exclude the needs and views of powerless sections of the population.

As argued earlier, science is not politically neutral because the research questions answered by scientists tend to be posed by some parties rather than others, and inherently build on specific societal problem definitions, values, and aspirations (Alrø and Kristensen 2002, Leeuwis 2004). Given a specific question, however, we have an obligation to be as rigorous, open, objective, and balanced as possible. Hence, our "partisan" role in the competing claims program lies primarily in the research questions we select. Much attention is given, therefore, to identifying researchable questions that are especially relevant to weaker groups. A range of methods can be used to elicit implicit questions and uncertainties (including poorly substantiated knowledge claims) that hinder progress in situations where claims are competing. This is done at different levels. Analysis and confrontation of knowledge gaps across levels leads to additional questions and redefinition of boundaries. Research teams set out to translate such implicit questions and uncertainties into coherent agendas for (social and natural science) research and knowledge mobilization. Alternative agendas are discussed with stakeholders, and eventually priorities for research will have to be negotiated among the various parties (including scientists).
Finally, ensure that the data and outcomes of research become available and accessible to all parties (while respecting and protecting the anonymity of respondents in the case of social science research) so that all stakeholders have access to similar information and knowledge. We strive to be as transparent as possible, and try to respond to any questions that may be raised in connection to our work. Also, we ensure that the prime responsibility for taking and negotiating decisions on the basis of information provided (especially in the "Design" phase) remains with the societal stakeholder, and that scientists do not "take over" the process or become implicated in selecting particular social and technical options.

\section{Turning Research into Societal Learning Experiences}

If we wish to ensure that stakeholders use research findings to overcome conflict, it is not enough to have an "end-of-pipe" communication strategy about results. Research will need to be carried out in an action research mode whereby societal stakeholders become active co-researchers and owners of the outcomes. Intensive interactions with stakeholders during the research serves not only to access and develop locally relevant questions and insights, but also to build up their confidence to become an equal partner in the subsequent diagnosis process, and to develop common starting points, shared objectives, and improved relationships among stakeholder groups (i.e., research can be seen as a form of "boundary work"). To such ends, research strategies and modes of communicating findings must be integrated with the design of learning experiences for stakeholders at and across different levels. Use is made of various forms of modeling (ranging from fuzzy cognitive mapping, 3-D GIS or relief scale models, gaming, to complex simulation and multiple goal models) that enhance insight into possible scenarios and trade-offs. In addition to modeling, other exploration, visualization, and feedback strategies, exchange visits, and pilot projects between societal governance levels may be organized. It is through such learning experiences that research findings can be fed into the negotiation platforms. Primacy will be given to methods and approaches that allow stakeholders to draw their own conclusions, rather than having them told by outsiders what the conclusions should be. Hence, we build on principles of "discovery learning" (Leeuwis 2004). 


\section{CONCLUSION}

Competing claims on natural resources are often played out at the local level but shaped by an everincreasingly complex interplay of policies and constraints at higher levels. For science to contribute to enabling the poor and/or marginalized to gain a voice in their future use of natural resources, emphasis needs to move away from providing solutions and plans for stakeholders to the support of negotiation between stakeholders based on negotiated shared understandings of the problems and opportunities for change. For this more modest role for science, we describe a methodology that is being used with stakeholders to address competing claims on natural resources in southern Africa, Brazil, and the Netherlands. These research programs can be seen as experiments in complex adaptive systems in which we seek to improve the contribution of science to important societal problems concerning use of natural resources. Through further development and application of the "NE-DEED" methodology (Fig. 2), natural and social sciences can assist in: (a) arriving at a comparative appraisal of the drivers of conflict as well as the opportunities to resolve competing claims; (b) opening up space for (social, technical, and/or institutional) innovation at different levels (local, national, regional, international) to address competing claims on natural resources; and (c) integrating results of the analyses in ongoing negotiation processes among stakeholders and providing recommendations for sustainable and equitable natural resource management.

Walker et al. (2006) highlight the difficulty in deriving and testing hypotheses when considering such complex and dynamic issues. Indeed, arriving at consensus on what constitutes a relevant hypothesis at the research program level proved to be challenging. Despite these problems, we have elaborated the following hypotheses:

- The occurrence and intensity of competing claims on natural resources increases with human pressures irrespective of natural resource endowment;

- Competing claims can be resolved through either new technical options, new institutional arrangements, or combinations of these;

- Resolving or coping with competing claims will be achieved through "win-win" solutions for a subset of stakeholders, which may at the same time be "win-lose" solutions for other sets of stakeholders;

- Better informed negotiations, using results from scientific analyses, will assist in resolving competing claims.

These hypotheses continue to stimulate debate, as is exemplified by renewed attention for the relation between economic development, resource endowment and conflict (Brunnschweiler and Bulte 2008, Ross 2004, Hauge and Ellingsen 1998) They also raise questions regarding the sociopolitical and ecological environments in which they are applicable.

The conceptual diagrams that describe the need to address the multiple scales and multi-level nature of constraints to innovation (Fig. 1) and the research methodology (Fig. 2) have already proved useful in focusing discussions with a wide range of stakeholders, including policy makers. Embarking on this research has brought research groups with very different paradigms and experiences together and assisted in developing new insights. Huge challenges remain, but we share these ideas at an early stage in the hope of learning from others who are conducting similar research into conducting complex adaptive system experiments in the real world.

Responses to this article can be read online at:

http://www.ecologyandsociety.org/voll3/iss2/art34/responses/

\section{Acknowledgments:}

We thank all of our colleagues who have contributed to the development of the ideas presented in this paper-in particular those who attended workshops and discussion meetings in Wageningen and southern Africa. This research is funded through the International Research and Education Fund (INREF) of Wageningen University, The Netherlands. 


\section{LITERATURE CITED}

Aarts, M. N. C. 1998. Een kwestie van natuur: een studie naar de aard en het verloop van communicatie over natuur en natuurbeleid [A matter of nature: a study into communication processes relating to nature and environmental policy-in Dutch]. Dissertation, Wageningen Agricultural University, Wageningen, The Netherlands.

Aarts, M. N. C., and C. M. J. V. Woerkum. 2002. Dealing with uncertainty in solving complex problems. Pages 421-435 in C. Leeuwis and R. Pyburn, editors. Wheelbarrows full of frogs: Social learning in rural resource management. Royal van Gorcum, Assen, The Netherlands.

Aarts, N. 2007. Self-organization in public space: of open networks and closed communities. MOPAN conference Learning for Interdependence. Leuven, The Netherlands.

Alrøe, H. F., and E. S. Kristensen. 2002. Towards a systemic research methodology in agriculture: rethinking the role of values in science. Agriculture and Human Values 19(1):3-23. ERRATUM

Anderies, J. M., M. A. Janssen, and E. Ostrom. 2004. A framework to analyse the robustness of social-ecological systems from an institutional perspective. Ecological and Society 9(1): 18. [online] URL: http://www.ecologyandsociety.org/vol9/ iss1/art18/.

Anderies, J. M., B. H. Walker, and A. P. Kinzig. 2006. Fifteen weddings and a funeral: Case studies and resilience-based management. Ecology and Society 11(1): 21. [online] URL: http://www.ecolog yandsociety.org/vol11/iss1/art21/.

Andersson, J.A. 1999. The politics of land scarcity: land disputes in Save Communal Land, Zimbabwe. Journal of Southern African Studies 25(4):553-578.

Becker, H. A., and G. Dewulf 1989. Terugkijken op toekomstonderzoek [Reviewing future research -in Dutch]. ISOR, University of Utrecht, Utrecht, The Netherlands.

Berkhout, F., A. Smith, and A. Stirling 2003. Socio-technical regimes and transition Contexts. University of Sussex, Brighton, UK.

Bousquet F., O. Barreteau, C. Le Page, C. Mullon, and J. Weber 1999. An environmental modelling approach: the use of multi-agent simulations. Pages 113-122 in F. Blasco and A. Weill, editors. Advances in environmental modelling. Elsevier, New York, New York, USA.

Bousquet F., and C. Le Page. 2004. Multi-agent simulations and ecosystem management: a review. Ecological Modelling 176:313-332.

Brunnschweiler, C. N., and E. H. Bulte. 2008. Linking natural resources to slow growth and more conflict. Science 320(May 6):616-617.

Carnevale, P. J. 2006. Creativity in the outcomes of conflict. Pages 414-435 in M. Deutsch, P. T. Coleman, and E.C. Marcus, editors. Handbook of conflict resolution. Second edition. Jossey-Bass, San Francisco, California, USA.

Carpenter, S., W. Brock, and P. Hanson. 1999. Ecological and social dynamics in simple models of ecosystem management. Conservation Ecology 3(2): 4. [online] URL: http://www.consecol.org/vol3/ iss $2 / \operatorname{art} 4 /$.

Cash, D. W., W. N. Adger, F. Berkes, P. Garden, L. Lebel, P. Olsson, L. Pritchard, and O. Young. 2006. Scale and cross-scale dynamics: governance and information in a multilevel world. Ecology and Society 11(2): 8. [online] URL: http://www.ecology andsociety.org/vol11/iss2/art18/.

Castells, M. 2004. The power of identity. The information age. Economy, society and culture, volume II. Blackwell, Cambridge, UK.

Chambers, R. 1994a. The origins and practice of participatory rural appraisal. World Development 22 (7):953-969.

Chambers, R. 1994b. Participatory rural appraisal (PRA): analysis of experience. World Development 22(9):1253-1268.

Cooke, B., and U. Kothari, editors. 2001. Participation: the new tyranny? Zed books, New York, New York, USA and London, UK.

de Wit, C. T. 1994. Resource use analysis in agriculture: a struggle for interdisciplinarity. Pages 42-55 in L. O. Fresco, L. Stroosnijder, J. Bouma, and $\mathrm{H}$. van Keulen, editors. The future of the land: mobilising and integrating knowledge for land use options. Wiley, Chichester, UK. 
di Castri, F. and M. Hadley. 1986. Enhancing the credibility of ecology: is interdisciplinary research for land use planning useful? GeoJournal 13: 299325.

Douthwaite, B., N. C. de Haan, V. Manyong, and D. Keatinge. 2001. Blending "hard" and "soft" science: the "follow-the-technology" approach to catalyzing and evaluating technology change. Conservation Ecology 5(2): 13 .

Edmunds, D., and E. Wollenberg. 2001. A strategic approach to multi-stakeholder negotiations. Development and Change 32(2):231-253.

Emery, M., and R. E. Purser 1996. The search conference: a powerful method for planning organizational change and community action. Jossey-Bass Publishers, San Francisco, California, USA.

Fals Borda, O. 1998. Theoretical foundations. Pages 157-173 in O. F. Borda, editor. People's participation: challenges ahead. Apex Press, Intermediate Technology Publications, New York, New York, USA and London, UK.

Funtowicz, S. O., and J. R. Ravetz. 1993. Science for the post-normal age. Futures 25(7):739-755.

Geels, F. 2002. Understanding the dynamics of technological transitions: a co-evolutionary and socio-technical analysis. Twente University Press, Enschede, The Netherlands.

Gibbons, M., C. Limoges, H. Nowotny, S. Schwartzman, P. Scott, and M. Trow 1994. The new production of knowledge: the dynamics of science and research in contemporary societies. Sage Publications, London, UK.

Gibson, C. C., E. Ostrom, and T. K. Ahn. 2000. The concept of scale and the human dimensions of global change: a survey. Ecological Economics 32:217-239.

Giddens, A. 1984. The constitution of society: outline of the theory of structuration. Polity Press, Cambridge, UK.

Giller, K. E., E. Rowe, N. de Ridder, and H. van Keulen. 2006. Resource use dynamics and interactions in the tropics: scaling up in space and time. Agricultural Systems 88(1):8-27.
Grin, J. F., F. Felix, B. Bos, and S. Spoelstra. 2004. Practices for reflexive design: lessons from a Dutch programme on sustainable agriculture. International Journal of Foresight and Innovation Policy $\mathbf{1}$ (1/2):126-149.

Gunderson, L. H., and C. S. Holling 2002. Panarchy: understanding transformations in human and natural systems. Island Press, Washington, D. C., USA.

Habermas, J. 1981. Theorie des kommunikativen handelns. Band 1: Handlungstrationalität und gesellschaftliche rationalisierung. Band 2: Zur kritik der funktionalistischen vernunft. Suhrkamp Verlag, Frunkfurt am Main, Germany.

Hagmann, J., E. Chuma, K. Murwira, M. Connolly, and P. Ficarelli. 2002. Success factors in integrated natural resource management R\&D: lessons from practice. Conservation Ecology 5(2): 29. [online] URL: http://www.ecologyandsociety.org/ vol5/iss2/art29/.

Hauge, W., and T. Ellingsen. 1998. Beyond environmental scarcity: causal pathways to conflict. Journal of Peace Research 35(3):299-317.

Hitchcock, R. K. 2002. "We are the first people": land, natural resources and identity in the central Kalahari, Botswana. Journal of Southern African Studies 28(4):797-824.

Hoppe, R., and S. Huys 2003. Werk op de grens tussen wetenschap en beleid: paradoxen en dilemma's [Work on the frontier between science and policy: paradoxes and dilemmas-in Dutch]. RMNO, The Hague, The Netherlands.

Jasanoff, S. 1990. The fifth branch: science advisers as policy makers. Harvard University Press, Cambridge, Massachusetts, USA.

Khan, S. M., and M. Quaddus. 2004. Group decision support using fuzzy cognitive maps for causal reasoning. Group Decision and Negotiation 13(5):463-480.

Kok, K., M. Patel, D. S. Rothman, and G. Quaranta. 2006. Multi-scale narratives from an IA perspective: Part I. European and Mediterranean scenario development. Futures 38(3):285-311. 
Koning, N., and R. Jongeneel. 2006. Food sovereignty and export crops: could ECOWAS create an OPEC for sustainable cocoa? Forum on Food Sovereignty, Niamey, Niger.

Leeuwis, C. 2000. Re-conceptualizing participation for sustainable rural development: towards a negotiation approach. Development and Change $\mathbf{3 1}$ (5):931-959.

Leeuwis, C. 2004. Communication for rural innovation: rethinking agricultural extension. Blackwell publishing, Oxford, UK.

Long, N. 1990. From paradigm lost to paradigm regained? The case for an actor-oriented sociology of development. European review of Latin American and Caribbean studies 49:3-32.

Long, N., and A. Long, editors. 1992. Battlefields of knowledge: the interlocking of social theory and practice in research and development. Routledge, New York, New York, USA and London, UK.

Long, N., and J. D. van den Ploeg. 1989. Demythologising planned intervention. Sociologia Ruralis 29(3/4):226-249.

MacMynowski, D. P. 2007. Pausing at the brink of interdisciplinarity: power and knowledge at the meeting of social and biophysical science. Ecology and Society 12(1): 20. [online] URL: http://www.e cologyandsociety.org/vol12/iss 1/art20/.

Moss, M. R. 2000. Interdisciplinarity, landscape ecology and the "transformation of agricultural landscapes." Landscape Ecology 15:303-311.

Mosse, D. 1995. Local institutions and power: the history and practice of community management of tank irrigation systems in India. Pages 144-156 in N. Nelson, and S. Wright, editors. Power and participatory development. Theory and practice. Intermediate Technologies, London, UK.

Nelson, N., and S. Wright 1995. Power and participatory development: theory and practice. Intermediate Technology Publications, London, UK.

Pijnenburg, B. 2004. Keeping it vague-discourses and practices of participatory in rural Mozambique. Dissertation, Wageningen University and Research Centre, Wageningen, The Netherlands.
Pretty, J. N., and R. Chambers. 1994. Towards a learning paradigm: new professionalism and institutions for agriculture. Pages 182-202 in I. Scoones, and J. Thompson, editors. Beyond farmer first. Rural people's knowledge, agricultural research and extension practice. Intermediate Technology Publications, London, UK.

Pretty, J. N., I. Guijt, J. Thompson, and I. Scoones 1995. Participatory learning and action: a trainer's guide. International Institute for Environment and Development, London, UK.

Pruitt, D. G., and P. J. Carnevale 1993. Negotiation in social conflict. Open University Press, Buckingham, UK.

Rip, A. 1995. Introduction of new technology: making use of recent insights from sociology and economics of technology. Technology Analysis and Strategic Management 7:417-431.

Rip, A., and R. Kemp. 1998. Technological change. Pages 327-399 in S. Rayner, and E. L. Malone, editors. Human Choice and Climate Change. Batelle Press, Columbus, Ohio, USA.

Robbins, P. 2003. Stolen fruit: the tropical commodities disaster. Zed Books and CTA, London, UK.

Röling, N. G. 1994. Platforms for decision-making about eco-systems. Pages 386-393 in L. O. Fresco, L. Stroosnijder, J. Bouma, and H. V. Keulen, editors. The future of the land: mobilising and integrating knowledge for land use options. Wiley, Chichester, UK.

Röling, N. G. 1996. Towards an interactive agricultural science. Journal of Agricultural Education and Extension 2(4):35-48.

Ross, M. L. 2004. What do we know about natural resources and civil war? Journal of Peace Research 41(3):337-356.

Sayer, J.A., and B. M. Campbell 2004. The science of sustainable development: local livelihoods and the global environment. Cambridge University Press, Cambridge, UK.

Scharpf, F. W. 1978. Interorganizational policy studies: issues, concepts and perspectives. Pages 
345-370 in K. Hanf and F. W. Scharpf, editors. Interorganizational policy making: Limits to coordination and central control. Sage Publications, London, UK.

Scoones, I. 1999. New ecology and the social sciences: what prospects for a fruitful engagement? Annual Review of Anthropology 28:479-507.

Scoones, I., and J. Thompson, editors. 1994. Beyond farmer first: rural people's knowledge, agricultural research and extension practice. Intermediate Technology Publications, London, UK.

Smits, R. 2002. Innovation studies in the 21st century: questions from a user's perspective. Technological Forecasting and Social Change 69 (9):861-883.

Stoorvogel, J. J., J. M. Antle, C. C. Crissman, and W. Bowen. 2004. The tradeoff analysis model: integrated bio-physical and economic modeling of agricultural production systems. Agricultural Systems 80(1):43-66.

Sultana, P., and P. Thompson. 2005. Consensus building for community based natural resource management. Pages 159-167 in J. Gonsalves, T. Becker, A. Braun, D. Campilan, H. d. Chavez, E. Fajber, M. Kapiriri, J. Rivaca-Caminade, and R. Vernoony, editors. Participatory research development for sustainable agriculture and natural resource management: a source book. The International Development Research Center (IDRC), Ottawa, Ontario, Canada.

van Gunsteren, H. 2006. Vertrouwen in democratie. Van Gennep, Amsterdam, The Netherlands.

van Ittersum, M. K., R. Rabbinge, and H. C. van Latesteijn. 1998. Exploratory land use studies and their role in strategic policy making. Agricultural Systems 58(3):309-330.

van Kasteren, J. 2002. Duurzame technologie ontwikkeling voor een houdbare wereld, deel 73 [Sustainable technology development for a sustainable world, issue 73-in Dutch]. Wetenschappelijke Bibliotheek, Natuur en Techniek, van Veen Magazines, Amsterdam, The Netherlands. van Veldhuizen, L., A. Waters-Bayer, and H. D. Zeeuw. 1997. Developing technology with farmers: a trainer's guide for participatory learning. Zed books, London, UK.

van Woerkum, C. 1997. Communicatie en interactieve beleidsvorming [Communication and interactive policy development-in Dutch]. Bohn Stafleu van Loghum, Houten, The Netherlands and Diegem, Belgium.

Vereijken, P. 1997. A methodical way of prototyping integrated and ecological arable farming systems (I/EAFS) in interaction with pilot farms. European Journal of Agronomy 7(1-3):235250 .

Wagemans, M., and J. Boerma. 1998. The implementation of nature policy in the Netherlands: platforms designed to fail. Pages 250-271 in N. G. Röling and M. A. E. Wagemakers, editors. Facilitatings sustainable agriculture: participatory learning and adaptive management in times of environmental uncertainty. Cambridge University Press, Cambridge, UK.

Walker, B. H., J. M. Anderies, A. P. Kinzig, and P. Ryan. 2006. Exploring resilience in socialecological systems through comparative studies and theory development: introduction to the special issue. Ecology and Society 11(1): 12. [online] URL: http://www.ecologyandsociety.org/vol11/iss1/art12/

Weisbord, M. R., and S. Janoff 1995. Future search: an action guide to finding common ground in organizations and communities. Berrett-Koehler Publishers, San Francisco, California, USA. 